\title{
Educação e tecnologias digitais em foco: precariedades presentes no contexto educacional brasileiro
}

\author{
Jéssica IUNG (1)
}

Universidade Federal do Rio Grande (FURG)

OPEN ACCESS

○

EDITADO POR

Raquel Freitag

AVALIADO POR

Noádia Silva

SOBRE OS AUTORES

Jéssica lung

Contribuiu com Marianna Rego. Papéis: conceitualização, escrita - análise e edição.

Marianna Rego Contribuiu com Jéssica lung. Papéis: conceitualização, escrita - análise e edição.

DATAS

Recebido: 02/07/2020

Aceito: 08/08/2020

Publicado: 14/08/2020

COMO CITAR

lung, J.; Rego, M. (2020). Educação e tecnologias digitais em foco: precariedades presentes no contexto educacional brasileiro. Revista da Abralin,

v. 19, n. 2, p. 1-4, 2020.

Marianna REGO @

Universidade Federal do Rio Grande (FURG)

RESUMO

Esta resenha busca destacar e analisar as principais reflexões apresentadas pela Prof ${ }^{a} \operatorname{Dr}^{\mathrm{a}}$ Ana Elisa Ribeiro (CEFET-MG). A conferência a qual é objeto deste trabalho abordou os ciclos da precariedade na utilização das Tecnologias Digitais da Informação e da Comunicação (TDIC) no âmbito educacional, seja na educação básica, seja na educação superior. Diante disso, Ribeiro destaca que esses ciclos são compostos pelos seguintes problemas: falta de infraestrutura e de qualificação dos profissionais da educação para o uso das tecnologias digitais. Dessa forma, a conferencista lançou olhar para o período pré, durante e pós-pandemia, que poderão possibilitar uma nova perspectiva de pesquisa e de trabalho com as TDIC na educação.

\section{ABSTRACT}

This review aims to highlight and to analyze the reflections presented by PhD professor Ana Elisa Ribeiro (CEFET-MG). The conference which is the object of this brief review addressed the precarious cycles of Information and Communication Technology (ICT) in the educational environment, either in basic education or in higher education. Therefore, Ribeiro emphasized that these cycles are compounded by the following problems: lack of 


\section{REVISTA DA ABRALIN}

infrastructure and lack of qualification of education professionals to use digital technologies. After all, the speaker shed light on the pre, during and post-pandemic period that may enable a new perspective of research and work with ICT in education.

\section{PALAVRAS-CHAVE}

Tecnologias digitais. Ensino. Ciclos da precariedade.

\section{KEYWORDS}

Digital technology. Teaching. Precarious cycles.

No evento Abralin ao vivo, a Prof. ${ }^{a}$ Dr. ${ }^{a}$ Ana Elisa Ribeiro proferiu a conferência Educação e Tecnologias digitais: ciclos da precariedade diante da pandemia. Esta foi transmitida pelo canal da Abralin no Youtube, no dia 25 de junho de 2020. Ribeiro é professora do Departamento de Linguagens e Tecnologias do Centro Federal de Educação Tecnológica de Minas Gerais (CEFET-MG) e também integra o Programa de Pós-Graduação em Estudos de Linguagens (POSLIN/CEFET-MG).

A fala da pesquisadora objetivou problematizar os ciclos da precariedade no uso das tecnologias digitais na educação. Esses ciclos, segundo Ribeiro, são compostos pela falta de infraestrutura dos espaços educacionais e de capacitação dos professores. Com base nisso, a presente resenha visa a analisar criticamente os principais tópicos discutidos durante a conferência.

Ao iniciar a palestra, a pesquisadora enfatizou que vivemos múltiplas crises ao mesmo tempo, a saber: política, sanitária e global. Antes de problematizar o que chamou de ciclos da precariedade, Ribeiro destacou que não a interessava refletir sobre a dicotomia escola pública e escola privada. Embora haja certa facilidade de acesso aos recursos na maioria dos contextos privados, corroboramos seu posicionamento, pois todas as práticas pedagógicas desenvolvidas, atualmente, têm sido tentativas improvisadas para driblar o caos.

Nesse sentido, a pesquisadora salienta a necessidade de discussões sobre Tecnologias Digitais da Informação e da Comunicação (TDIC) que vão além da questão tecnicista, pois não se trata apenas de ter um equipamento disponível na escola ou em casa. Sendo assim, a primeira parte do ciclo da precariedade é o fato de não reconhecermos o acesso à internet como uma necessidade infraestrutural. Até o início da pandemia, vivíamos sem Ambientes Virtuais de Aprendizagem (AVA) bem estruturados, com acessos negados (bloqueios de sites), com data show fixo em sala de aula e com equipamentos obsoletos, que não acompanharam nossas demandas.

Há pelo menos 30 anos, pesquisas têm sido elaboradas, principalmente no âmbito da Pós-Graduação, cujos apontamentos sobre as tecnologias digitais são tímidos. Essas práticas, apontadas por Ribeiro, dizem respeito a nossa dificuldade, ainda, de entender que educação e tecnologia andam juntas e são fluidas. Ademais, o ciclo da precariedade pré-pandemia pautou-se muito na comparação 


\section{REVISTA DA ABRALIN}

entre o analógico e o digital. No entanto, diversas vezes esquecemos que existe uma relação corporecurso direta. Por isso, Ribeiro destacou que não são produtivas as considerações positivas e negativas em relação às atividades feitas de forma analógica e digital, respectivamente, pois cada modo de atuação apresenta prós e contras. O recurso não age por si só, pois ele depende de nós, ou seja, do nosso engajamento.

Tomemos, assim, o smartphone como exemplo, já que é o dispositivo mais representativo da Cultura Digital em que estamos e que estaremos imersos, pré, durante e pós-pandemia. Conforme reiterou Ribeiro, já aceitamos a essencialidade desse dispositivo móvel, mas não o legitimamos para fins educacionais, pois ainda lidamos com uma série de leis as quais o proíbe nas escolas. Nesse momento, a pandemia inaugurou uma "nova forma de pilotagem" (37:25) em que o imaginário repleto de malefícios vem sendo substituído por usos radicais, cheios de imprevistos e de improvisos. Apesar disso, essas utilizações estão sendo positivas, mesmo diante de condições precárias.

Dessa forma, concordamos com a autora quando ela ressaltou que, no presente momento, temos a possibilidade de projetar uma educação linguística acolhedora das TDIC. Para isso, podemos tomar o que Ribeiro chamou de entrada abrupta nas TDIC como um atalho para desenhar as práticas pedagógicas pós-pandemia. Assim, precisamos olhar para o letramento digital enquanto um processo, e não apenas como usos tímidos e pontuais das tecnologias em sala de aula.

Tendo em vista esse processo, a qualificação docente é a segunda parte do ciclo da precariedade. Isso porque, em diferentes contextos educacionais, o professor não tem o devido suporte para buscar especializações. Tal qualificação, no momento atual, não garante que iremos ter todas as respostas; porém, a instrumentalização e a formação continuada são caminhos para que consigamos ter objetivos claros para o uso das TDIC. Para tanto, é essencial que se rompam as "desconexões criminosas" (1:03:14), ou seja, que seja ampliado o investimento em políticas públicas eficientes. Entendemos como políticas públicas eficientes aquelas que tratam o acesso à internet como infraestrutura - priorizam como um direito de todos - e que incentivam financeiramente o professor a dedicar-se a pesquisas teórico-práticas alicerçadas ao seu contexto de trabalho.

Se tais políticas são criadas, mantidas e ampliadas, os documentos normativos, como a Base Nacional Comum Curricular (BNCC), poderão ser melhor explorados. A partir das considerações sobre os ciclos da precariedade do passado e do presente, Ana Elisa Ribeiro destacou que a entrada abrupta na realização de atividades remotas poderá acarretar um vislumbramento do que já estava na BNCC como temática transversal. A importância de pensar os usos das TDIC está presente nas competências gerais da educação básica, como pode-se verificar no seguinte trecho:

[...] 5. Compreender, utilizar e criar tecnologias digitais de informação e comunicação de forma crítica, significativa, reflexiva e ética das diversas práticas sociais (incluindo as escolares) para se comunicar, acessar e disseminar informações, produzir conhecimentos, resolver problemas e exercer protagonismo e autoria na vida pessoal e coletiva. (BRASIL, 2018, p. 9)

Dessa forma, é possível observar, a partir do contexto de ciclos da precariedade, bem como do reconhecimento da BNCC, que o nosso problema continuará caso não ocorra uma mudança de mentalidade (mindset) frente ao uso das tecnologias digitais (LANKSHEAR; KNOBEL, 2008) e de 


\section{REVISTA DA ABRALIN}

desenvolvimento das políticas públicas educacionais brasileiras. Tal mudança vai ao encontro do que foi colocado por Ribeiro, pois reconhecemos que não basta tecnologizar o espaço físico (colocar equipamentos) ou plataformizar a escola (criar AVA pouco estruturado).

Ribeiro também mencionou que há muitas pesquisas sobre atividades as quais utilizam e refletem acerca do uso das tecnologias em sala de aula. Entretanto, essas inserções escolares são pontuais, isto é, são feitas para um fim específico - a realização da pesquisa. Dessa forma, não há uma continuidade desse tipo de atividade nos ambientes educacionais. Com base nessas considerações, compreendemos que é de suma importância repensar o papel do linguista aplicado nas pesquisas realizadas nesse âmbito.

Os instrumentos de coleta de dados, ou seja, as atividades que utilizam as TDIC, não podem mais ser feitas de forma tímida, porque essas devem visar à transformação e à inserção social. Assim, é importante refletir sobre o posicionamento adotado diante de nossos projetos, pois "pensar nas consequências práticas das nossas elucubrações teóricas é uma questão de escolha, em outras palavras, é uma questão política". (RAJAGOPALAN, 2003, 135). Por fim, salientamos que o período atual é oportuno para repensarmos nosso compromisso social, pois, como afirmou Ribeiro, o momento é fértil para elaborar e reelaborar pesquisas.

\section{REFERÊNCIAS}

BRASIL. Ministério da Educação (MEC). Base Nacional Comum Curricular. Brasília: 2017. Acesso em: 08 fev. 2020. Disponível em: <http://basenacionalcomum.mec.gov.br/images/BNCC_EI_EF_110518_versaofinal_site.pdf>. Acesso em: 08 fev. 2020.

EDUCAÇÃO e tecnologias digitais: ciclos da precariedade diante da pandemia. Conferência apresentada por Ana Elisa Ribeiro. [s.l., s.n], 2020.1 vídeo (1h 33min 25seg). Publicado pelo canal da Associação Brasileira de Linguística. Disponível em: https://www.youtube.com/watch?v=-lfTZT7oFI\&t=329s. Acesso em: 29 jun 2020.

LANKSHEAR, Colin. KNOBEL, Michele. Digital literacies: Concepts, Policies and Practices. New York: Peter Lang Inc., International Academic Publishers, 2008.

RAJAGOPALAN, Kanavillil. Por uma linguística crítica: linguagem, identidade e a questão ética. São Paulo: Parábola Editorial, 2003. 